\section{俩 Heighten Science \\ P U B L I C I T I O N S Corporation ISSN 2575-0135}

\title{
Role of polyamine metabolism in plant pathogen interactions
}

\author{
Magda Pal* and Tibor J anda \\ Agricultural Institute, Centre for Agricultural Research, Hungarian Academy of Sciences, \\ H-2462 Martonvásár, POB 19, Hungary
}

*Address for Correspondence: Magda Pal, Agricultural Institute, Centre for Agricultural Research, Hungarian Academy of Sciences, H-2462 Martonvásár, POB 19, Hungary, Tel: +3622-569-502; Fax: +36-22-569-576; Email: pal.magda@agrar.mta.hu

Submitted: 30 November 2017

Approved: 06 December 2017

Published: 07 December 2017

Copyright: @ 2017 Pal M, et al. This is an open access article distributed under the Creative Commons Attribution License, which permits unrestricted use, distribution, and reproduction in any medium, provided the original work is properly cited.

Abbreviations: ADC: Arginine by Arginine Decarboxylase; DAO: Diamine Oxidases; DFMO: Alpha-Difluoromethylornithine; HR: Hypersensitive Reaction; ODC: Ornithine Decarboxylase; PA: Polyamine; PAO: Polyamine Oxidase; PCD: Programmed Cell Death; PUT: Putrescine; SAMDC: S-Adenosylmethionine Decarboxylase; SPD: Spermidine; SPDS: Spermidine Synthase; SPM: Spermine; SPMS: Spermine Synthase

\section{Abstract}

Polyamines are aliphatic amines found in all living cells, and they are necessary for several fundamental cell processes. Their protective role against various abiotic stress factors has been reported in different plant species, while the mechanism by which polyamines act during plantmicrobe interaction is still poorly understood. The several types of the interactions between the plants and the microbes outline a divers and complex picture of the action mechanisms. The present review focuses on this aspect of the mode of action of polyamines and polyamine metabolism during biotroph and necrotroph interactions between plants and pathogens. It seems that apoplastic metabolism of polyamines of the host and the accumulation of $\mathrm{H} 2 \mathrm{O} 2$ as a result of polyamine catabolism play important signalling role in plant-pathogen interactions. The manipulation of the members of the polyamine-induced signalling pathways could increase the host plant resistance to biotic stresses.

\section{Introduction}

Polyamines (PAs) are aliphatic amines found in all living cells. The most abundant PAs in plants are putrescine (PUT), spermidine (SPD) and spermine (SPM), the latter two are also called as higher PAs. However, the levels of individual PAs vary depending on the plant species or organ and on the developmental stage. The biosynthetic pathway of these PAs is well documented [1]. Briefly, PUT is synthesized by the decarboxylation of ornithine, catalysed by ornithine decarboxylase (ODC), or indirectly by the decarboxylation of arginine by arginine decarboxylase (ADC), via agmatine. Higher PAs (SPD and SPM) are produced by the sequential addition of aminopropyl moieties to the PUT skeleton through enzymatic reactions catalyzed by the SPD and SPM synthases. S-adenosylmethionine decarboxylase (SAMDC) is responsible for the synthesis of decarboxylated S-adenosylmethionine which is used for the addition of the aminopropyl moiety. Besides the diamine oxidases (DAOs) and PA oxidase (PAOs), which catalyse the terminal catabolism of PAs in the apoplast, PAs also undergo rapid interconvertion in the PA-cycle in the peroxisomes, where the partial and/or full backconversion of SPM to SPD and of SPD to PUT are catalyse by special PAOs (Pál et al. 2015). The metabolism of PAs in fungi shows some differences compared to plants. Compare to plants, not all fungi contain SPM. In fungi SPD is the most important PA, which involved in all the functions such as the regulation of cell proliferation and differentiation, vegetative growth, spore germination, sporulation or dimorphic transition, probably in all fungi [2-4]. Another pronounced difference is, that in plants PUT is synthesized by two alternative pathways catalysed by ODC and ADC, but in fungi, there is a unique pathway PUT formation in which the enzyme ODC plays the central role. The synthesis of higher PAs (SPD and SPM) functions similarly as in plants, as also the terminal catabolism of PAs. Although completed with some additional enzymatic reactions the back-conversion of SPM into SPD, and SPD to PUT is also occurred in fungi [4]. 
Due to their cationic nature, they are able to interact with negatively charged macromolecules (such as nucleic acids, phospholipids, proteins) and stabilize their structure, especially under stress conditions. According to these bindings, PAs influence the membrane permeability characteristics, induce changes in protein function $[1,5]$. Besides their direct protective role, their binding to the chromatin cause alteration in the availability of genomic sites to DNA or RNA polymerases [6]; furthermore several protein kinases have been shown to be influenced at the transcriptional or post-translational level by PAs [7]. In addition PA metabolism is also related to several other metabolic pathways, such as proline, and the synthesis of plant hormones and signalling molecules, such as ethylene, $\mathrm{H}_{2} \mathrm{O}_{2}$ or $\mathrm{NO}$ (Pál et al.). Although several studies have been published on both the changes of PA levels during abiotic stress (Kovács et al.,; Pál et al.,) and protective effects of PAs against various abiotic stress factors, such as drought or cadmium (Szalai et al.,; Tajti et al.), the mechanism by which PAs act during plant-microbe interaction is sometimes contradictory. In addition, the several types of the interactions between the plants and the microbes resulted in a divers and complex action mechanisms [8].

PAs are not only essential to maintain cell viability, but function as signalling molecules regulating many of the responses that help the plants to cope with biotic stresses and also to build symbiotic interactions. The present review focuses on this aspect of the mode of action of PAs and attempts to find answers to the following questions: is there a relationship between accumulation of PAs and plant biotic stress resistance and what are the differences between biotroph and necrotroph interactions?

\section{Plant-pathogen interactions}

Biotrophic pathogens: Biotrophic fungal pathogens colonize and require living plant cells to survive because they obtain nutrients from living host cells (Glazebrook, 2005). During a compatible interaction between plants and pathogens, in the green island regions - surrounding the infection sites, induction of photosynthesis and delay in senescence were found - fungal pathogens induces the PA synthesis of the host, as it was found in the case of the compatible interaction between barley and Puccinia hordei Otth. (Greenland and Lewis, 1984) or Blumeria graminis f. sp. hordei [9]. Similarly, accumulation of the free and conjugated forms of SPD was found already after 3 days and of SPM 7 days after powdery mildew infection, in both susceptible and resistant wheat genotypes. As the precursor of SPD and SPM, PUT is, probably used up for synthesis of SPD and SPM, which were then stored in conjugated form (Pál et al. 2013). This suggested that the accumulation of PAs was a general response to inoculation; furthermore, differences between the initial and induced levels of PAs were not correlated with the degree of tolerance to powdery mildew. However, the opposite was found, when powdery mildew resistant and susceptible barley cultivars have been described, and the resistant cultivar accumulates higher PUT and SPD levels than the susceptible one after infection [10]. Relationships between the PA contents and the level of pathogen resistance were also found in oat cultivars. Both resistant and susceptible oat cultivars in response to Blumeria graminis f.sp. avenae or Blumeria graminis f.sp. hordey, showed significant differences in the free PA levels. The resistant genotype showed higher level of SPD than the sensitive one, and showed a significant increase in it after Blumeria graminis f.sp. avenae (host interaction) inoculation, and similar pattern was detected for ADC activity. In the case of Blumeria graminis f.sp. hordey (non-host interaction) infection increased levels of PUT was found in the sensitive genotype [11]. Increased levels of free PUT and SPD and of conjugated forms of PUT, SPD and SPM have already been reported 1-4 d after infection in an incompatible interaction, between powdery mildew and barley. In addition not only increased level of PAs, but increased activity of the synthetic enzymes, ODC, ADC and SAMDC were detected [12]. The early accumulation of PUT and induction of ODC and ADC gene expression were found in wheat after Fusarium graminearum inoculation [13]. 
Changes in PA levels have also been found in oat after crown rust (Puccinia coronata f. sp. avenae) inoculation, and differences in PA contents between resistant and susceptible cultivars were associated with increased pre-penetration and penetration resistance. Increased amount of SPD and SPM, together with increased level of PA degradation were found in the resistant cultivar at early stages of the infection process. In addition, increased ADC activity in the susceptible cultivar was detected during prepenetration, and exogenous PA treatment reduced the appressorium formation in the same oat cultivars [14]. In most cases induction of PA synthesis has been reported during biotroph pathogen infection, however, in the highly susceptible sugarcane infected with Ustilago scitaminea reduced free PA content has been reported [15].

Increased gene expression level of genes encoding PA synthesis enzymes was found in flax seedlings infected with pathogenic strains of Fusarium culmorum and Fusarium oxysporum and the non-pathogenic strain of Fusarium oxysporum. The highest induction of the mRNA level was found in the case of ODC and ADC after Fusarium culmorum inoculation, while the gene expression of PAO did not change. However, the highest total PA level, especially cell wall-bound SPD content was found in the plants infected by the pathogenic Fusarium oxysporum, suggesting that locally accumulated PAs can directly inhibit pathogen growth or reinforce the cell wall to restrict pathogen invasion. Lowest induction in the gene expression levels and PA accumulation was detected in the case of the non-pathogenic Fusarium oxysporum strain. Differences observed between the two pathogenic strains also suggested, that the two pathogens have different mechanisms for plant tissues penetration, and they also induced different defence mechanism in flax seedlings [16].

According to these, fungal infection of plants might be controlled by a specific inhibitor of PA synthesis. ODC (responsible for PUT synthesis in fungi) enzyme can be irreversibly blocked by alpha-difluoromethylornithine (DFMO), which has no effect on ADC (not found in fungi, only in plants). DFMO provided protection against three biotrophic fungal pathogens, namely leaf rust, stem rust and powdery mildew in wheat [17]. Originally, it was thought that inhibition of PA synthesis alone would be enough to control the growing of pathogen fungi. However, these treatments (e.g. DFMO) were not always completely efficient against pathogens, which may be due to an increase in the PA uptake by the pathogens from host. When wheat spikes were treated with DFMO and subsequently inoculated with Fusarium graminearum conidia, DFMO did not display inhibitory effects on the fungus. Indeed DFMO added to the medium induced the expression of a transcriptional regulator and the trichodiene synthase, which have role in deoxynivalenol mycotoxin biosynthesis. In addition up-regulation of ODC, and some type of PA transporter was found in F. graminearum cultures when treated with DFMO [18]. These results suggested that the inhibition of PA biosynthesis together with inhibition of plant PA transporters, may be useful target as a way to avoid this secondary effect.

Similarly to the fungal pathogens, biotrophic interactions between viruses or bacteria and plants also revealed that during HR and the induced programmed cell death (PCD) the activity of ODC and the level of PAs increased in tobacco plants infected with tobacco mosaic virus [19], or in pepper plants after infection with Xanthomonas campestris [20]. In tobacco during infection with the biotrophic bacterium Pseudomonas viridiflava an increase of apoplastic SPM levels was detected. Enhancement of host PA levels either due to overexpression of ADC gene or PAs treatments, decreased the growth of bacteria, while inhibition PAO enzymes enhanced it [21].

As the generation of $\mathrm{H}_{2} \mathrm{O}_{2}$ via the terminal catabolism of PAs plays a role in PA-related signalling processes (Pál et al., 2015), PA metabolisms may be involved in penetration resistance against biotroph pathogens. The formation of $\mathrm{H}_{2} \mathrm{O}_{2}$ resulting from the enhanced activities of DAO and PAO, could be responsible for the hypersensitive 
reaction (HR) observed in barley after powdery mildew infection [12]. It has also been suggested that SPM is the most important PA in plant defence against pathogens in incompatible host-pathogen interactions [22]. Therefore, it is an interesting aspect to examine the role of different PAOs in controlling HR and/or PCD in plants during pathogen attacks [23].

Necrotroph pathogens: Necrotroph pathogens kill the host cells at very early stages in the infection and feed on the remains. According to this it seems that PCD in the host would merely make life easier for the pathogen (Glazebrook, 2005). Infection of tobacco by the Sclerotinia sclerotiorum resulted in increased gene expression level and activity of ADC in the host tissues, as well as PUT and SPM accumulation in the apoplast. The increased PA exodus and the apoplastic terminal catabolism has also role in the pathogen-induced necrosis [24]. It was also found that overexpression of ADC in transgenic tobacco plants or infiltration with exogenous PAs, led to increased necrosis after infection with $S$. sclerotiorum. In contrast, inhibition of apoplastic DAO and PAO decreased leaf necrosis during the fungal infection [21].

However, the results on necrotroph pathogens are sometimes contradictory. Infection of tobacco leaves with Peronospora tabacina, Alternaria tenuis, Erysiphe cichoracearum, Pseudomonas tabaci or tobacco mosaic virus resulted in lower level of PUT and SPD in the infected plants, compared to the control [25]. These results suggested that the changes were not related to the type of pathogens (fungi, bacterium or virus) or the type of mechanism (biotroph or necrotroph) but to the severity of damage symptoms. The SPD synthase overexpressor transgenic tomato lines, which accumulate higher levels of SPD than the wild-type plants were more susceptible to Botrytis cinerea (necrotroph), while responses to Alternaria solani (necrotroph) or Pseudomonas syringae pv tomato (biotroph) were similar to the wild-type plants (Nambeesan et al., 2012). The inhibition of DAO activity in chickpea resistant to the necrotroph fungal pathogen, Ascochyta rabiei resulted in reduced resistance to the pathogen [26]. In accordance with this, constitutive overexpression of cotton PAO gene- responsible for the back-conversion of SPM to SPD - in Arabidopsis improved resistance to Verticillium dahlia (Mo et al., 2015).

\section{Conclusion}

Thus, on one hand PAs serve as nutrients from the host cell to support further fungal growth, but on the other hand plants also need them to limit the fungal multiplication. It can be concluded that accumulation and further oxidation of PAs in the apoplast of host plant cells catalysed by DAO and PAO may occur in a similar, although not identical way during plant responses induced by biotroph or necrotroph pathogens. These responses play a beneficial role in plant defence mechanisms against biotrophic pathogens that depend on living tissue, while help necrotroph pathogens to colonize host tissues. Thus, apoplastic PAs play important roles in plant-pathogen interactions, and modulation of host PA metabolism, may lead to significant changes in host susceptibility to different pathogens. Importance to keep the homeostasis of PAs, revealing that imbalance of SPD impairs host signalling cascades leading to alterations in the immune responses. Another important aspect is that the accumulation of $\mathrm{H}_{2} \mathrm{O}_{2}$ as a result of PA catabolism plays an important signalling role in plant-pathogen interactions, suggesting that the manipulation of the members of the PA-induced signalling pathway could increase the host plant resistant to biotic stresses. However, the picture is often more complicated as the presence of PAs in both plants and pathogenic fungi makes it difficult to identify their respective contribution to PA accumulation in infected organs. Further research needs to clarify the exact role of PA metabolism in plant-pathogen interactions.

\section{Acknowledgements}

This work was supported by a grant from the National Research, Development and Innovation Office KH 124472, which is gratefully acknowledged. 


\section{References}

1. Tiburcio AF, Altabella T, Bitrián M, Alcázar R. The roles of polyamines during the lifespan of plants: from development to stress. Planta. 2014; 240: 1-18. Ref.: https://goo.gl/zUs4tU

2. Valdés-Santiago L, Guzmán-De-Peña D, Ruiz- Herrera J. Life without putrescine: disruption of the gene-encoding polyamine oxidase in Ustilago maydis odc mutants". FEMS Yeast Research. 2010; 10 : 928-940. Ref.: https://goo.gl/7LEY83

3. Vuohelainen $S$, Pirinen $E$, Cerrada-Gimenez $M$, Keinänen TA, Uimari $A$, et al. Spermidine is indispensable in differentiation of 3T3-L1 fibroblasts to adipocytes. J Cell Mol Med. 2010; 14: 16831692. Ref.: https://goo.gl/Q14RNN

4. Valdés-Santiago L, Cervantes-Chávez JA, León-Ramírez CG, Ruiz-Herrera J. Polyamine metabolism in fungi with emphasis on phytopathogenic species. J Amino Acids. 2012; 2012: 837932. Ref.: https://goo.gl/YP53u5

5. Hamdani S, Yaakoubi H, Carpentier RJ. Polyamines interaction with thylakoid proteins during stress. Photochem Photobiol B. 2011; 104: 314-319. Ref.: https://goo.gl/F1RrFS

6. Lightfoot $\mathrm{HL}$, Hall J. Endogenous polyamine function- the RNA perspective. Nucl Acids Res. 2014 42: 11275-11290. Ref.: https://goo.gl/MSAuGr

7. Jang EK, Min KH, Kim SH, Nam SH, Zhang S, et al. Mitogen-activated protein kinase cascade in the signaling for polyamine biosynthesis in tobacco. Plant Cell Physiol. 2009; 50: 658-664. Ref.: https://goo.gl/YycgVH

8. Hussain SS, Ali M, Ahmad M, Siddique KH. Polyamines: natural and engineered abiotic and biotic stress tolerance in plants. Biotechnol Adv. 2011; 29: 300-311. Ref.: https://goo.gl/Het7fu

9. Coghlan SE, Walters DR. Polyamine metabolism in 'green-islands' on powdery mildew-infected barley leaves: possible interactions with senescence. New Phytol. 1990; 116: 417-424. Ref.: https://goo.gl/G78REr

10. Asthir B, Spoor W, Duffus C. Involvement of polyamines, diamine oxidase and polyamine oxidase in resistance of barley to Blumeria graminis f. sp. hordei. Euphytica. 2004; 136: 307-312. Ref.: https://goo.gl/zUrqdL

11. Montilla-Bascón G, Rubiales D, Prats E. Changes in polyamine profile in host and non-host oatpowdery mildew interactions. Phytochem Lett. 2014; 8: 207-212. Ref.: https://goo.gl/1v1Vkp

12. Cowley T, Walters DR. Polyamine metabolism in barley reacting hypersensitively to the powdery mildew fungus Blumeria graminis f. sp. hordei. Plant Cell Environ. 2002; 25: 461-468. Ref.: https://goo.gl/LNfrS4

13. Gardiner DM, Kazan K, Praud S, Torney FJ, Rusu A, et al. Early activation of wheat polyamine biosynthesis during Fusarium head blight implicates putrescine as an inducer of trichothecene mycotoxin production. BMC Plant Biol. 2010; 10: 289. Ref.: https://goo.gl/3zLsco

14. Montilla-Bascón G, Rubiales D, Altabella T, Prats E. Free polyamine and polyamine regulation during pre-penetration and penetration resistance events in oat against crown rust (Puccinia coronata f. $\mathrm{sp}$. avenae). Plant Pathol. 2016; 65: 392-401. Ref.: https://goo.gl/ZqunNv

15. Legaz ME, Armas RD, Piñon D, Vicente $C$. Relationships between phenolics-conjugated polyamines and sensitivity of sugarcane to smut (Ustilago scitaminea). J Exp Bot. 1998; 49: 1723-1728. Ref.: https://goo.gl/bWEvSo

16. Wojtasik W, Kulma A, Namysł K, Preisnerand M, Szopa J. Polyamine metabolism in flaxin response to treatment with pathogenic and non-pathogenic Fusarium strains Frontiers Plant Sci. 2015; 6: 291. Ref.: https://goo.gl/5k33bB

17. Weinstein LH, Osmeloski JF, Wettlaufer SH, Galston AW. Protection of wheat against leaf and stem rust and powdery mildew diseases by inhibition of polyamine metabolism. Plant Sci. 1987; 51: 311 316. Ref.: https://goo.gl/75K1KD

18. Crespo-Sempere A, Estiarte N, Marin S, Sanchis V, Ramos AJ. Targeting Fusarium graminearum control via polyamine enzyme inhibitors and polyamine analogs. Food Microbiol. 2015; 49: 95-103. Ref.: https://goo.gl/frZmCu

19. Negrel J, Vallee JC, Martin C. Ornithine decarboxylase activity and the hypersensitive reaction to tobacco mosaic-virus in Nicotiana tabacum. Phytochem. 1984; 23: 2747-2751. Ref.: https://goo.gl/qi3oWx

20. Kim NH, Kim BS, Hwang BK. Pepper arginine decarboxylase is required for polyamine and gammaaminobutyric acid signaling in cell death and defense response. Plant Physiol. 2013; 162: 20672083. Ref.: https://goo.gl/xn7n3o 
21. Marina M, Maiale SJ, Rossi FR, Romero MF, Rivas El, et al. Apoplastic polyamine oxidation plays different roles in local responses of tobacco to infection by the necrotrophic fungus Sclerotinia sclerotiorum and the biotrophic bacterium Pseudomonas viridiflava. Plant Physiol. 2008; 147: 21642178. Ref.: https://goo.gl/WKow32

22. Mitsuya $Y$, Takahashi $Y$, Berberich $T$, Miyazaki $A$, Matsumura $H$, et al. Spermine signalling plays a significant role in the defense response of Arabidopsis thaliana to cucumber mosaic virus. J Plant Physiol. 2009; 166: 626-643. Ref.: https://goo.gl/Pe4Njx

23. Moschou PN, Roubelakis-Angelakis KA. Polyamines and programmed cell death. J Exp Bot. 2014; 65: 1285-1296. Ref.: https://goo.gl/xfsP7C

24. Moschou PN, Paschalidis KA, Delis ID, Andriopoulou AH, Lagiotis GD, et al. Spermidine exodus and oxidation in the apoplast induced by abiotic stress is responsible for $\mathrm{H}_{2} \mathrm{O}_{2}$ signatures that direct tolerance responses in tobacco. Plant Cell. 2008; 20: 1708-1724. Ref.: https://goo.gl/tUkhoN

25. Edreva A. Tobacco polyamines as affected by stresses induced by different pathogens. Biol. Plant. 1997; 40: 317-320. Ref.: https://goo.gl/V9kGh4

26. Rea G, Metoui O, Infantino A, Federico R, Angelini R. Copper amine oxidase expression in defense responses to wounding and Ascochyta rabiei invasion. Plant Physiol. 2002; 128: 865-875. Ref.: https://goo.gl/RTD5tu

27. Estiarte N, Crespo-Sempere A, Marín S, Sanchis V, Ramos AJ. Exploring polyamine metabolism of Alternaria alternata to target new substances to control the fungal infection. Food Microbiol. 2017; 65: 193-204. Ref.: https://goo.gl/1yh2yp 